\title{
Comparison of characteristics among Korean American male smokers between survey and cessation studies
}

\author{
Sun S. Kim ${ }^{1 *}$, Seongho $\mathrm{Kim}^{2}$, Colleen $\mathrm{McKay}^{1}$, Douglas Ziedonis ${ }^{1}$ \\ ${ }^{1}$ University of Massachusetts Medical School, Department of Psychiatry, Worcester, Massachusetts, USA; \\ *Corresponding Author: sun.kim@umassmed.edu \\ ${ }^{2}$ School of Social Welfare, Korean Bible University, Seoul, South Korea
}

Received 19 March 2013; revised 6 May 2013; accepted 23 May 2013

Copyright (C) 2013 Sun S. Kim et al. This is an open access article distributed under the Creative Commons Attribution License, which permits unrestricted use, distribution, and reproduction in any medium, provided the original work is properly cited.

\section{ABSTRACT}

This study compared characteristics of Korean American men in two studies: a telephone survey with a random sample of Korean American men who reported daily smoking versus a smoking cessation clinical trial with a convenience sample of Korean American men who reported smoking at least 10 cigarettes a day. Guided by the Theory of Planned Behavior (TPB), both studies attempted to explain how much its theoretical variables (attitudes, perceived social norms, and self-efficacy) would explain quit intentions in Korean American men. Participants in the cessation study were less likely to have health insurance coverage $\left(x^{2}[2,271]=138.31, p=0.001\right)$ than those in the survey study. The cessation group was more likely to smoke in indoor offices $\left(x^{2}[1,231]=18.09, p=0.003\right)$ and had higher nicotine dependence than the survey group $\left(t_{269}\right.$ $=3.32, p=0.001$ ) but these differences became insignificant when only those who smoked 10 or more cigarettes were compared. Participants in the cessation study had more positive attitudes towards quitting $\left(t_{267}=4.99, p<0.001\right)$, stronger perceived social norms favoring quitting $\left(t_{269}=\right.$ $5.63, p<0.001)$ and greater quit intentions $\left(t_{268}=\right.$ 9.86, $p<0.001)$ at baseline than those in the survey study. Korean American men are more likely to have a quit intention and make a quit attempt when they have more positive and fewer negative attitudes towards quitting and perceive stronger social norms favoring quitting. To motivate Korean American men to quit smoking, clinicians should underscore the immediate health benefits of quitting, promote quitting with cessation aids to reduce perceived risks of quitting in anticipation of withdrawal symptoms, and encourage family members to relate firm antismoking messages.

Keywords: Smoking; Smoking Cessation; Theory of Planned Behavior; Korean

\section{INTRODUCTION}

Korean American men are more likely to be current smokers than the general US male population, whereas Korean American women smoke at a rate similar to that of the general US female population $[1,2]$. It was reported that $71 \%$ of Korean American men die from smoking-related cancer deaths versus $30 \%$ of the general US population $[3,4]$. Only $24 \%$ of Korean American smokers in California had ever been advised to quit by a physician as opposed to $46 \%$ for the general population of smokers in the same state $[5,6]$. Recently several studies have been conducted to test the efficacy of a smoking cessation intervention in this group and some had positive cessation outcomes [7-10]. It has been argued that participants in a clinical trial of smoking cessation differ from the general population of smokers, which is often addressed as a major limitation of the study. Nevertheless, it is largely unknown how the two groups differ from each other. Thus, we examined how a convenience sample of Korean American men who participated in a cessation clinical trial [8] would differ from a random sample of Korean American men in a telephone survey study (unpublished data).

Both of the studies were guided by the Theory of Planned Behavior (TPB) $[11,12]$ and both used the same measures. Among many theories proposed for behavior change, the TPB has been adopted widely to explicate 
smokers' intentions to quit smoking and an actual quit attempt, including among Korean Americans [13-16]. The TPB proposes that attitudes, perceived social norms, and perceived behavior control are antecedents to behavioral intention, which then determines actual performance of the behavior [11,12]. Attitudes toward the behavior refer to the degree to which a person has favorable or unfavorable evaluations or appraisals of the behavior. Perceived social norms are defined as perceived social pressures to perform or not perform the behavior. The concept of perceived behavior control is the belief that one can successfully execute the behavior that is required to produce the outcome. The theory posits that the more favorable the attitudes and the perceived social norms toward quitting and the greater the perceived behavior control in quitting, the stronger the individual's intention to perform the behavior should be.

Ajzen constructed the term perceived behavior control, borrowing its theoretical definition from Bandura's selfefficacy that is the perception of one's competence to perform the required task [17]. The self-efficacy theory explicates that acquiring and maintaining new skills such as quitting smoking and resisting smoking temptations are mediated by self-efficacy [18]. Bandura proposed four major sources of information that can strengthen self-efficacy: one's actual accomplishment, vicarious experience, verbal persuasion, and physiological state. A meta-analysis of TPB studies indicated that self-efficacy explains more of the variance in behavioral intentions than perceived behavior control [19]. Thus, instead of perceived behavior control, self-efficacy is often used in TPB studies [13-16] and we also used this variable.

Only one study [20] exists to date that examined the applicability of the TPB to smoking behavior in Korean American men. Nicotine dependence and past-year quit attempts explained $15 \%$ of variance in quit intentions and attitudes and perceived social norms explained an additional $20 \%$ of the variance. Perceived social norms were found to be the strongest predictor of quit intentions and actual quit attempts, which might be related to Korean cultural upbringing whereby people are inculcated with the values of collectivism and conformity [21]. Self-efficacy was, however, found not to be a significant factor of quit intentions or actual quit attempts. Similar to our finding, Vietnamese men who had smoking-related family conflicts were more likely to have higher intentions to quit smoking than those who did not have the conflicts [22].

The primary hypothesis of this study was that Korean American men in a smoking cessation study would not differ in demographics and smoking behavior from Korean American men in a tobacco survey who were randomly selected. The secondary hypothesis was that participants in the cessation study would have more positive attitudes towards quitting and perceive stronger social norms favoring quitting than participants in the survey study. Finally, we hypothesized that the TPB variables would have strong explanatory power of quit intentions in Korean American male smokers.

\section{METHOD}

\subsection{Design}

This is a descriptive research study comparing characteristics of participants between two studies: the first study is a general-population telephone survey of Korean Americans who reported daily smoking and the second is a smoking cessation study with a convenience sample of Korean Americans. Both studies were approved by the Institutional Review Board of the University of Massachusetts Medical School. Due to a small number of women in both studies, only data from men were used in this study.

\subsection{Sample}

Participants were Korean American men who 1) selfidentified as Korean, 2) aged 18 or older, and 3) had smoked at least one cigarette per day for the past six months. In addition, participation in the cessation study was restricted to individuals who had smoked at least 10 cigarettes a day in order to receive nicotine patches [23].

\subsection{Procedure}

The survey was conducted from November 2008 to September 2010. First, a list of households with popular Korean surnames such as "Kim" or "Lee" was created from an online telephone directory InfoSpace.com. The households were identified from the top 100 cities for the Korean population in the 2000 US Census [24]. Second, 11,051 households were randomly selected from the list based on computer-generated numbers. Third, the selected households were called up to seven times at various hours of a day, including evenings and weekends. Those who answered the call were briefly informed about the purpose of the study. If the household was determined to be Korean, the person who answered the call was further asked regarding the presence of any adult smokers. In total 7235 households (65.5\%) were screened and $4667(42.2 \%)$ were determined to be Korean residences.

Of the Korean households, $576(12.3 \%)$ had at least one adult who was smoking daily and of these, smokers in 486 households $(10.4 \%)$ were all males. We interviewed only one smoker per household and stopped interviewing male smokers after the 166th interview, which was the estimated sample size needed to detect relationships among the TPB variables. The overall response rate 
was $36.2 \%$ from all households that possibly had Korean male smokers, including those who could not be screened due to disconnected lines and no answers after seven call attempts. The survey was conducted in English or Korean depending on the preference of the person being interviewed. Three bilingual Korean Americans who had been working in the United States for at least 15 years conducted the interview.

The cessation study had 131 participants who were recruited from advertisements in regional Korean news media such as newspapers and radios between October 2009 and August 2012. Of the total sample, 105 were Korean American men. The study is described in detail with its preliminary findings $(\mathrm{N}=30)$ regarding cessation outcomes [8]. Its baseline data were used in this study.

\subsection{Measures}

All scale measures but one (a measure of attitudes toward smoking) had been used in previous studies with Korean Americans, and processes undertaken for the cross-cultural validation have been reported in detail elsewhere [20,25-27]. Attitudes towards quitting were assessed using the Perceived Risks and Benefits Questionnaire [28]. It was translated into a Korean version and then the Korean version was translated back to English by a different person multiple times. After the third round of translation and back-translation, a Korean version of the questionnaire was pilot-tested with five Korean Americans who were current and former smokers and then further revised based on their feedback.

\subsubsection{Demographic Data}

These data included age, marital status, years of education, employment status, annual family income, health insurance coverage, and religion.

\subsubsection{Acculturation}

It was assessed using a brief form of the Suinn-Lew Asian Self-Identify Acculturation Scale [29]. The measure consists of the five items (language spoken, language preferred, language read, childhood friends, and cultural identity) that had the highest item-to-total correlations among the 21 items in its full version [30]. Scores for each item range from " 1 = very Korean-culture oriented" to " 5 = very American-culture oriented", and the scale score is the mean score of the five items.

\subsubsection{Smoking Behavior}

Information was gathered regarding age of smoking onset, use of other tobacco products in addition to cigarettes, smoking indoors at home and at work, any quit attempts made in the last year, and number of past-year quit attempts for which abstinence lasted for at least 24 hours.

\subsubsection{Nicotine Dependence}

The Fagerström Test for Nicotine Dependence is a sixitem scale assessing physical dependence on nicotine [31]. The scale score is the sum of the scores of the six items and ranges from 0 to 10 . Higher scores indicate more dependence on nicotine.

\subsubsection{Alcohol Use}

Alcohol consumption and its associated problems were assessed using the Alcohol Use Disorders Identification Test [32]. It consists of 10 items and each item score ranges from 0 to 4 . Scores above eight are indicators of harmful alcohol use.

\subsubsection{Attitudes}

The Perceived Risks and Benefits Questionnaire consists of 40 items: 18 items on perceived risks (i.e., negative attitudes: "I will be less able to concentrate," and "I will miss the taste of cigarettes") and 22 items on perceived benefits (i.e., positive attitudes: "I will smell cleaner," and "I will feel proud that I was able to quit") [28]. Participants were asked to rate their perception of the likelihood of each item if they were to stop smoking on a 7 -point Likert-type scale $(1=$ no chance at all, $7=$ certain to happen). The mean score is the scale score for each subscale.

\subsubsection{Perceived Social Norm}

A modified version of Jee's [33] measure was used to assess subjective norms toward quitting. It consists of two items regarding normative beliefs (i.e., "I believe that my family [my friends] want me to quit smoking") and motivation to comply (i.e., "I am willing to comply with the belief"). Scores for each item range from " $-3=$ strongly disagree" to " +3 = strongly agree", and the scale score is the sum of the scores of the two items. The score for the second item is reversed if the first item has a negative score. For example, a person who strongly disagrees with the normative belief $(-3)$ also earns the same score for motivation to comply if the person has strong motivation to comply with the disagreement. Findings from previous studies $[8,13]$ indicate that smokers are often conflicted by the discrepancy between the social norms for family and the social norms for friends who also smoke. Thus, scores of the two-referent groups were not combined.

\subsubsection{Self-Efficacy}

Instead of perceived behavior control, self-efficacy was assessed using the scale that was developed by Velicer and others [34] and later modified by Kim and colleagues [27] to reflect Korean-specific smoking-prone situations. Participants were asked to rate their confi- 
dence in resisting smoking temptation in 10 high-risk situations such as "When I feel tense or anxious," and "When I wake up in the morning." The measure is a 5point Likert-type scale and scores for each item can range from " 1 = completely unconfident" to " $5=$ completely confident". The scale score is the sum of the scores of the ten items.

\subsubsection{Intention to Quit Smoking}

This was the dependent variable and assessed using a 7-point Likert-type scale with four items (e.g., "I intend to quit smoking within the next two weeks," and "I made a decision to quit smoking within the next two weeks") [20]. Scores range from " $1=$ most unlikely" to " $7=$ most likely" and the scale score is the mean of the scores of the four items. Higher scores indicate stronger intentions to quit smoking.

\subsection{Data Analysis}

Data were analyzed with SPSS version 20.0. Descriptive statistics were used to assess demographics, smoking behavior, and psychosocial variables including TPB variables. Listwise deletion was used to handle missing data that were approximately $5 \%$ of the total data. Chisquare tests and two-sample $t$-tests or Mann-Whitney $U$ tests were performed to examine differences in demographics and psychosocial variables between the two studies. Due to different inclusion criteria in number of cigarettes smoked per day (one versus 10 cigarettes), we also compared only those who reported smoking at least 10 cigarettes per day. Data from the two studies were then combined and linear regression analyses were performed to identify factors associated with intentions to quit smoking among Korean American men. The regression analyses were performed by entering all variables that showed significant correlations with quit intentions and then eliminating non-significant variables in an order of first the TPB variables, second smoking behavior variables, and third demographics. A $p$ value of $<0.05$ was considered statistically significant for all analyses.

\section{RESULTS}

A total of 271 Korean American men (166 from the survey study and 105 from the cessation study) participated (Table 1). Ages ranged from 20 to 85 with a mean age of $50.5(\mathrm{SD}=12.4)$ and more than half of them had at least a 4 -year college education. Exactly half (50\%) of them had smoked for 30 or more years and about one third of them (35\%) smoked the first cigarettes within 30 minutes after waking. More than half (57\%) smoked between 10 and 20 cigarettes a day and $16 \%$ smoked more than a pack a day. Approximately one (25\%) out of four reported that they were smoking indoors in houses and in offices.

Parametric ( $t$-test) or and nonparametric (Mann-Whitney $U$ ) tests did not show differences in significance levels and hence, we reported results of $t$-tests. Except for health insurance coverage, the two groups were similar in demographics (Table 1). The cessation group was more likely to be uninsured than the survey group $\left(\chi^{2}[2\right.$, $271]=138.31, p=0.001)$. The cessation group was about twice as likely to smoke indoors in offices as the survey group $\left(\chi^{2}[1,231]=18.09, p=0.003\right)$. However, no difference was found in the rate of indoor-house smoking. As expected, nicotine dependence was higher $\left(t_{245}\right.$ $=3.43, p=0.001$ ) in the cessation group than in the survey group. The cessation group was far more likely than the survey group to perceive positive attitudes towards quitting $\left(t_{267}=4.99, p<0.001\right)$ and stronger family norm $\left(t_{269}=5.32, p<0.001\right)$ and peer norm for quitting $\left(t_{269}=\right.$ $5.63, p<0.001)$. The former also had greater intentions to quit smoking $\left(t_{269}=9.86, p<0.001\right)$ than the latter. The two were similar in negative attitudes towards quitting and self-efficacy in quitting.

The comparison of participants who smoked 10 or more cigarettes per day showed no differences in the rate of indoor-office smoking and severity of nicotine dependence between the two studies. On the other hand, selfefficacy that was not different in the total sample became significantly different $\left(t_{235}=2.73, p<0.01\right)$. Participants in the cessation study had much higher self-efficacy at baseline than those in the survey study. All other findings regarding attitudes towards smoking, perceived social norms and quit intentions remained same as before with the total sample.

Regression analysis for each study group yielded identical results in terms of factors associated with quit intentions and thus, data from the two studies were combined in the final regression model (Table 2). Individuals who had serious past-year quit attempts, greater positive attitudes (benefits of quitting), fewer negative attitudes (risks of quitting), and stronger perceived family and peer norms were more likely to have a greater intention to quit smoking $(\mathrm{F}[5,265]=44.11, p<0.001)$. These factors accounted for $44 \%$ of the variance in intentions to quit smoking. Indoor-house smoking, age of smoking onset, and self-efficacy were all significant factors of the quit intention in a single variable analysis but became insignificant when other covariates were entered in the model.

\section{DISCUSSION}

Korean American men who participated in the cessation study were similar to those in the survey study who were randomly selected in terms of demographics and smoking history except for health insurance coverage. 
Table 1. Characteristics of participants in survey, cessation study, and the total sample.

\begin{tabular}{|c|c|c|c|}
\hline \multirow{2}{*}{ Variable } & Survey $(\mathrm{N}=166)$ & Cessation $(\mathrm{N}=105)$ & Total $(\mathrm{N}=271)$ \\
\hline & Mean $\pm \mathrm{SD} / \mathrm{N}(\%)$ & Mean $\pm \mathrm{SD} / \mathrm{N}(\%)$ & Mean $\pm \mathrm{SD} / \mathrm{N}(\%)$ \\
\hline Age & $50.9 \pm 13.5$ & $48.7 \pm 10.2$ & $50.5 \pm 12.4$ \\
\hline Marital status (married) & $127(76.5)$ & $89(84.8)$ & $216(79.7)$ \\
\hline Years of education & $14.5 \pm 2.7$ & $15.1 \pm 2.6$ & $14.7 \pm 2.7$ \\
\hline Employment (yes) & $138(83.1)$ & $95(90.5)$ & $233(86.0)$ \\
\hline $\begin{array}{l}\text { Family income }(n=193) \\
\text { Under } \$ 20,000 \\
\$ 20,000-\$ 59,999 \\
\$ 60,000-\$ 99,999 \\
\$ 100,000 \text { or more }\end{array}$ & $\begin{array}{l}21(13.0) \\
57(35.4) \\
47(29.2) \\
36(22.4)\end{array}$ & $\begin{array}{l}13(12.4) \\
50(47.6) \\
29(27.6) \\
13(12.4)\end{array}$ & $\begin{array}{c}34(12.8) \\
107(40.2) \\
76(28.6) \\
49(18.4)\end{array}$ \\
\hline $\begin{array}{l}\text { Medical insurance coverage } \\
\text { Private } \\
\text { Medicaid/Medicare } \\
\text { None }\end{array}$ & $\begin{array}{l}66(39.8) \\
42(25.3) \\
58(34.9)\end{array}$ & $\begin{array}{l}30(28.6) \\
15(14.3) \\
60(57.1)\end{array}$ & $\begin{array}{c}96(35.4) \\
57(21.0) \\
118(43.5)\end{array}$ \\
\hline Religion (Christianity) & $110(66.3)$ & $67(63.8)$ & $177(65.3)$ \\
\hline Acculturation $(1-5)$ & $1.9 \pm 0.7$ & $1.8 \pm 0.4$ & $1.9 \pm 0.6$ \\
\hline Age at smoking onset & $19.7 \pm 3.7$ & $19.3 \pm 2.8$ & $19.6 \pm 3.2$ \\
\hline Smoking duration & $30.5 \pm 11.8$ & $28.8 \pm 9.5$ & $29.4 \pm 11.9$ \\
\hline Nicotine dependence $(1-10)^{* *}$ & $4.1 \pm 2.4$ & $5.2 \pm 1.9$ & $4.8 \pm 2.1$ \\
\hline Indoor house smoking (yes) & $41(24.7)$ & $29(27.6)$ & $70(25.8)$ \\
\hline Indoor office smoking (yes) $^{* *}$ & $24(17.6)$ & $35(36.8)$ & $59(25.5)$ \\
\hline Past-year quit attempts (yes) & $91(54.8)$ & $64(61.0)$ & $155(57.2)$ \\
\hline Number of past-year quit attempts & $3.2 \pm 2.3$ & $3.2 \pm 3.6$ & $3.2 \pm 3.0$ \\
\hline Alcohol use problems & $5.4 \pm 5.7$ & $6.1 \pm 5.6$ & $5.7 \pm 5.7$ \\
\hline Positive attitudes $(1-7)^{* * *}$ & $5.1 \pm 1.1$ & $5.7 \pm 0.8$ & $5.3 \pm 1.1$ \\
\hline Negative attitudes $(1-7)$ & $4.2 \pm 1.1$ & $4.3 \pm 0.9$ & $4.2 \pm 1.0$ \\
\hline Perceived family norm $(-6-+6)^{* * *}$ & $4.1 \pm 2.0$ & $5.1 \pm 1.0$ & $4.5 \pm 1.8$ \\
\hline Perceived peer norm $(-6-+6)^{* * *}$ & $1.0 \pm 2.6$ & $2.8 \pm 2.8$ & $1.7 \pm 2.8$ \\
\hline Self-efficacy $(10-50)$ & $27.4 \pm 7.3$ & $29.0 \pm 8.3$ & $28.0 \pm 7.7$ \\
\hline Behavioral Intention $(1-7)^{* * *}$ & $3.4 \pm 2.2$ & $5.7 \pm 1.2$ & $4.5 \pm 2.2$ \\
\hline
\end{tabular}

Note: $\mathrm{SD}=$ standard deviation, ${ }^{* *} p<0.01,{ }^{* * *} p<0.001$.

Table 2. A multivariate regression analysis of an intention to quit smoking $(\mathrm{N}=271)$.

\begin{tabular}{lcccc}
\hline Variable & $\begin{array}{c}\text { Unstandardized } \\
\text { Coefficient }\end{array}$ & Standard Error & $\begin{array}{c}\text { Standardized } \\
\text { Coefficient }\end{array}$ & $p$-value \\
\hline Past-year quit attempt & 0.59 & 0.21 & 0.13 & $<0.01$ \\
Positive attitudes towards quitting & 0.53 & 0.11 & 0.31 & $<0.001$ \\
Negative attitudes towards quitting & -0.30 & 0.10 & -0.14 & $<0.01$ \\
Perceived family norm favoring quitting & 0.42 & 0.07 & 0.34 & $<0.001$ \\
Perceived peer norm favoring quitting & 0.15 & 0.04 & 0.19 & $<0.001$ \\
\hline
\end{tabular}

Compared to the survey group, the cessation group was less likely to have health insurance coverage. The cessation study was conducted in a metropolitan city where most Korean Americans were employed in a small business that does not mandate health insurance coverage [35]. Thus, participants in the cessation study were less 
likely to have health insurance than those in the survey one. In addition, those without coverage might have been more willing to participate in the cessation study because all treatments were offered at no cost to them.

The cessation group differed largely from the survey group with regard to the TPB variables. The cessation group had more positive attitudes towards quitting, perceived stronger social norms favoring quitting, and had greater self-efficacy than the survey group even prior to the intervention. As expected the cessation group had greater intentions to quit smoking than the survey group. These findings were in support of Ajzen's [11,12] proposition that attitudes, perceived social norms and selfefficacy (i.e., perceived behavior control) are antecedents to behavioral intentions and actual behavior change.

Consistent with the previous study [20], perceived family norm was found to be the strongest predictor of quit intentions. Korean American men who perceived a stronger family norm favoring quitting had a greater quit intention. Others also found that having family conflicts related to smoking was significantly associated with Vietnamese American men's intentions to quit smoking [22]. Thus, clinicians should educate and train Asian family members to convey strong messages against smoking and encourage their men to quit smoking. In the final model, history of past-year quit attempts, attitudes and perceived social norms accounted for $44.4 \%$ of the variance in quit intentions. These findings were in support of a previous study with Korean American men [20]. The percent of variance explained by the TPB variables in this study was within the range (23 - 45\%) of what others [13-16] have found.

Findings related to self-efficacy have been inconclusive in studies testing the applicability of the TPB. Some $[14,15]$ found the significant explanatory power of the variable in relation to quit intentions, whereas others [13, 16] found no relationship between the two. In this study, self-efficacy was not a significant factor of quit intentions, which is similar to a previous study conducted with Korean American men [20]. Structural equation modeling indicated that perceived behavior control (or selfefficacy) did not explain the variance of quit intentions due to its conceptual and measurement issues [36]. The researcher argued that the construct "perceived behavior control" might have limited power in predicting an addiction behavior such as smoking cessation. On the other hand, based on the structural modeling, the old model (the Theory of Reasoned Action) that did not include perceived behavior control provided a good fit to the data [36].

The present study has several limitations. First, participants in the survey study were recruited from an online telephone directory that listed only landline telephone numbers. Thus, those who did not subscribe to a landline service might have been excluded from the study. The response rate was low although our response rate was comparable to those (36.0 to $60.3 \%$ ) in similar survey studies [37,38]. It has been suggested that a random telephone survey with a low response rate still has excellent demographic representativeness [39]. The present study was the first attempt to examine how Korean American men in a smoking cessation study would differ from the general population of Korean American male smokers.

In conclusion, more than half of the participants in the survey study reported having made serious quit attempts within the past year. They could have been more likely to succeed in quitting if they had received professional assistance [23]. Findings suggest that those who perceive more positive and fewer negative attitudes toward quitting and stronger social norms favoring quitting are more likely to have a quit intention. Clinicians should utilize these aspects in order to motivate Korean American men to quit smoking. They should emphasize the immediate health benefits of quitting, promote quitting with cessation aids to reduce perceived risks of quitting, and encourage family members to relate firm anti-smoking messages.

\section{ACKNOWLEDGEMENTS}

The study was funded by the American Lung Association (SB78709-N) and the National Institute on Drug Abuse (5K23DA02124302 ) to the first author. The contents are solely the responsibilities of the authors and do not represent the official views of the American Lung Association and the National Institute on Drug Abuse.

\section{REFERENCES}

[1] Caraballo, R.S., Yee, S.L., Gfroerer, J. and Mirza, S.A. (2008) Adult tobacco use among racial and ethnic groups living in the United States, 2002-2005. Public Health Research, Practice and Policy, 5, 1-9. http://www.cdc.gov/pcd/issues/2008/jul/07 0116.htm

[2] California Health Interview Survey (2011) California Health Interview Survey: Adult survey.

http://www.chis.ucla.edu/signup.asp

[3] Leistikow, B.N., Chen, M. and Tsodikov, A. (2006) Tobacco smoke overload and ethnic, state, gender, and temporalcancer mortality disparities in Asian-Americans and Pacific Islander-Americans. Preventive Medicine, 42, 430434. doi:10.1016/j.ypmed.2005.12.015

[4] Centers for Disease Control and Prevention (2005) Tobacco use and cessation counseling - Global health professionals survey pilot study, 10 countries. Morbidity and Mortality Weekly Report, 54, 505-509.

[5] Tong, E.K., Tang, H., Chen Jr., M.S. and McPhee, S.J. (2011) Provider smoking cessationadvice among California Asian-American smokers. American Journal of Health Promotion, 25, S70-S74. 
doi:10.4278/ajhp.100611-QUAN-186

[6] Al-Delaimy, W.D., White, M.M., Gilmer, T., Messer, K., Gilmer, T., Zhu, S.-H., et al. (2008) The California Tobacco Control Program: Can we maintain the progress? Results from the California Tobacco Survey, 1990-2005. University of California, San Diego.

http://www.cdph.ca.gov/programs/tobacco/Documents/C TCP-CTSReport1990-2005.pdf

[7] Fang, C.Y., Ma, G.X., Miller, S.M., Tan, Y., Su, X. and Shives, S. (2006) A brief smoking cessation intervention for Chinese and Korean American smokers. Preventive Medicine, 43, 321-324. doi:10.1016/j.ypmed.2006.06.009

[8] Kim, S.S., Kim, S.H. and Ziedonis, D. (2012) Tobacco dependence treatments for Korean Americans: Preliminary findings. Journal of Immigrant and Minority Health, 14, 395-404. doi:10.1007/s10903-011-9507-0

[9] McDonnell, D.D., Kazinets, Z., Lee, H.J. and Moskowitz, J.M. (2011) An internet-based smoking cessation program for Korean Americans: Results from a randomized controlled trial. Nicotine \& Tobacco Research, 13, 336-343. doi:10.1093/ntr/ntq260

[10] Zhu, S.H., Cummins, S.E., Wong, S., Gamst, A.C., Tedeschi, G.J. and Reyes-Nocon, J. (2012) The effects of a multilingual telephone quitline for Asian smokers: A randomized controlled trial. Journal of the National Cancer Institute, 104, 299-310. doi:10.1093/jnci/djr530

[11] Ajzen, I. (1988) Attitudes, personality and behavior. Dorsey Press, Chicago.

[12] Ajzen, I. (1991) The theory of planned behavior. Organizational Behavior and Human Decision Processes, 50, 179-211. doi:10.1016/0749-5978(91)90020-T

[13] Burkhalter, J.E., Warren, B., Shuk, E., Primavera, L. and Ostroff, J.S. (2009) Intention to quit smoking among lesbian, gay, bisexual, and transgender smokers. Nicotine \& Tobacco Research, 11, 1312-1320. doi:10.1093/ntr/ntp140

[14] Dohnke, B., Weiss-Gerlach, E. and Spies, C.D. (2011) Social influences on the motivation to quit smoking: Main and moderating effects of social norms. Addictive Behaviors, 36, 286-293. doi:10.1016/j.addbeh.2010.11.001

[15] Hu, S.C. and Lanese, R.R. (1998) The applicability of the theory of planned behavior to the intention to quit smoking across workplaces in southern Taiwan. Addictive Behaviors, 23, 225-237. doi:10.1016/S0306-4603(97)00045-2

[16] Rise, J., Kovac, V., Kraft, P. and Moan, I.S. (2008) Predicting the intention to quit smoking and quitting behaviour: extending the theory of planned behaviour. British Journal of Health Psychology, 13, 291-310. doi:10.1348/135910707X187245

[17] Bandura, A. (1977) Self-efficacy: Toward a unifying theory of behavioral change. Psychological Review, 84, 191215. doi:10.1037/0033-295X.84.2.191

[18] Bandura, A. (1990) Perceived self-efficacy in the exercise of control over AIDS infection. Evaluation and Program Planning, 13, 9-17. doi:10.1016/0149-7189(90)90004-G

[19] Armitage, C.J. and Conner, M. (2001) Efficacy of the theory of planned behavior: A meta-analytic review. British Journal of Social Psychology, 40, 471-499. doi:10.1348/014466601164939

[20] Kim, S.S. (2008) Predictors of short-term smoking cessation among Korean American men. Public Health Nursing, 25, 516-525. doi:10.1111/j.1525-1446.2008.00738.x

[21] Kim, S.S., Son, H. and Nam, K.A. (2005) The sociocultural context of Korean American men's smoking behavior. Western Journal of Nursing Research, 27, 604-623. doi:10.1177/0193945905276258

[22] Tsoh, J.Y., Tong, E.K., Gildengorin, G., Nguyen, T.T., Mdayil V., Wong, C., et al. (2011) Individual and family factors associated with intention to quit among male Vietnamese American smokers: Implications for intervention development. Addictive Behaviors, 36, 294-301. doi:10.1016/j.addbeh.2010.11.009

[23] Fiore, M.C., Jaen, C.R., Baker, T.B., Bailey, W.C., Bennett, G., Benowitz, N.L. et al. (2008) Treating tobacco use and dependence: 2008 update. Clinical practice guideline. USDHHS, US Public Health Services, Rockville.

[24] Korean American Coalition-Census Information Center (2000) Top 100 cities/places in the United States for the Korean population. California State University, Los Angeles.

http://www.calstatela.edu/centers/ckaks/census/top 100 c ities.pdf

[25] Kim, S.S., Fang, H., DiFranza, J., Ziedonis, D. and Ma, G. (2012) Gender differences in the Fagerström test for nicotine dependence in Korean Americans. Journal of Smoking Cessation, 7, 31-36. doi:10.1017/jsc.2012.5

[26] Kim, S.S., Gulick, E.E., Nam, K.A. and Kim, S.H. (2008) Psychometric properties of the alcohol use disorders identification test: A Korean version. Archives of Psychiatric Nursing, 22, 190-199. doi:10.1016/j.apnu.2007.07.005

[27] Kim, S.S., Kim, S.H. and Gulick, E.E. (2009) Cross-cultural validation of smoking abstinence self-efficacy scale with Korean-American men. Issues in Mental Health Nursing, 30, 122-130. doi:10.1080/01612840802370582

[28] McKee, S.A., O’Malley, S.S., Salovey, P., Krishnan-Sarin, S. and Mazure, C.M. (2005) Perceived risks and benefits of smoking cessation: Gender-specific predictors of motivation and treatment outcome. Addictive Behaviors, 30, 423-435. doi:10.1016/j.addbeh.2004.05.027

[29] Suinn, R.M., Rickard-Figueroa, K., Lew, S. and Vigil, P. (1987) The Suinn-Lew Asian Self-Identity Acculturation scale: An initial report. Educational and Psychological Measurement, 47, 401-407. doi: $10.1177 / 0013164487472012$

[30] Leong, F.T. and Chou, E.L. (1998) Developing brief versions of the Suinn-Lew Asian Self-Identity Acculturation (SL-ASIA) scale for counseling research. Asian American Pacific Islander Journal of Health, 6, 13-24.

[31] Heatherton, T.F., Kozlowski, L.T., Frecker, R.C. and Fagerstrőm, K.O. (1989) The Fagerstrőm test for nicotine dependence: A revision of the Fagerstrőm tolerance questionnaire. British Journal of Addiction, 86, 1119-1127. doi:10.1111/j.1360-0443.1991.tb01879.x

[32] Saunders, J.B., Aasland, O.G., Babor, T.F. and De La 
Fuente Jr., M.G. (1993) Development of the Alcohol Use Disorders Identification Test (AUDIT): WHO collaborative project on early detection of persons with harmful alcohol consumption-II. Addiction, 88, 791-804.

[33] Jee, Y.O. (1993). Development of an instrument based on Ajzen's theory of planned behavior. Korean Journal of Nursing Query, 2, 102-117.

[34] Velicer, W.F., DiClemente, C.C., Rossi, J.S. and Prochaska, J.O. (1990) Relapse situations and self-efficacy: An integrative model. Addictive Behaviors, 15, 271-283. doi:10.1016/0306-4603(90)90070-E

[35] Yoon, I.J. (1998) Who is my neighbor? Koreans' perceptions of Blacks and Latinos as employees, customers, and neighbors. Development and Society, 27, 49-75.

[36] Bledsoe, L.K. (2006) Smoking cessation: An application of theory of planned behavior to understanding progress through stages of change. Addictive Behaviors, 31, 12711276. doi:10.1016/j.addbeh.2005.08.012

[37] Keeter, S., Miller, C., Kohut, A., Groves, R.M. and Presser, S. (2000) Consequences of reducing nonresponse in a national telephone survey. Public Opinion Quarterly, 64, 125-148. doi:10.1086/317759

[38] O'Toole, J., Sinclair, M. and Leder, K. (2008) Maximizing response rates in household telephone surveys. $B M C$ Medical Research Methodology, 8, 71. doi:10.1186/1471-2288-8-71

[39] Keeter, S., Kennedy, C., Dimock, M., Best, J. and Craighill, P. (2006) Gauging the impact of growing nonresponse on estimates from a national RDD telephone survey. Public Opinion Quarterly, 70, 759-779. doi:10.1093/poq $/ \mathrm{nfl} 035$ 